\title{
Total alkaloids of Rubus aleaefolius Poir. inhibit the STAT3 signaling pathway leading to suppression of proliferation and cell cycle arrest in a mouse model of hepatocellular carcinoma
}

\author{
JINYAN ZHAO ${ }^{1,2}$, WEI LIN ${ }^{1,2}$, ZHIYUN CAO ${ }^{1}$, LIYA LIU ${ }^{1}$, QUNCHUAN ZHUANG $^{1,2}$, \\ XIAOYONG ZHONG ${ }^{1}$, ZHENFENG HONG ${ }^{1}$ and $\mathrm{JUN} \mathrm{PENG}^{1,2}$ \\ ${ }^{1}$ Academy of Integrative Medicine Biomedical Research Center; ${ }^{2}$ Fujian Key Laboratory of Integrative Medicine \\ on Geriatrics, Fujian University of Traditional Chinese Medicine, Fuzhou, Fujian 350122, P.R. China
}

Received April 15, 2013; Accepted June 14, 2013

DOI: $10.3892 /$ or.2013.2585

\begin{abstract}
Signal transducer and activator of transcription 3 (STAT3) plays a critical role in cell survival and proliferation and is constitutively activated in many types of human cancers including hepatocellular carcinoma (HCC). Therefore, it is a major focus in the development of anticancer agents. Rubus aleaefolius Poir. has been demonstrated to be effective in the treatment of HCC. However, the precise mechanism of its anticancer activity remains largely unknown. Using HepG2 cells and a HCC mouse xenograft model, in the present study we evaluated the effect of the total alkaloids of Rubus aleaefolius Poir. (TARAP) on tumor growth in vitro and in vivo and investigated the underlying molecular mechanisms. We found that TARAP inhibited the proliferation of HepG2 human HCC cells and blocked G1/S cell cycle progression. In addition, TARAP treatment suppressed STAT3 phosphorylation in tumor tissues. Consequently, the inhibitory effect of TARAP on STAT3 activation resulted in the inhibition of proliferation. Moreover, TARAP altered the expression of several important target genes of the STAT3 signaling pathway, such as decreased expression of cyclinD1, cyclinE, cyclin-dependent kinase (CDK) 4 and CDK2 as well as upregulated p21. These results suggest that suppression of the STAT3 signaling pathway leading to inhibition of proliferation and cell cycle arrest may be one of the mechanisms of the anticancer activity of TARAP against HCC.
\end{abstract}

Correspondence to: Professor Zhenfeng Hong or Professor Jun Peng, Academy of Integrative Medicine Biomedical Research Center, Fujian University of Traditional Chinese Medicine, 1 Huatuo Road, Minhou Shangjie, Fuzhou, Fujian 350122, P.R. China

E-mail: zfhong1953@163.com

E-mail: pjunlab@hotmail.com

Key words: total alkaloids of Rubus aleaefolius Poir., proliferation, hepatocellular carcinoma, cell cycle, signal transducer and activator of transcription 3

\section{Introduction}

Hepatocellular carcinoma ( $\mathrm{HCC}$ ), the most common primary hepatic malignancy, is the third leading cause of cancer-related deaths worldwide (1). In recent years, the incidence of HCC has been rising in developing countries and in most developed countries $(2,3)$. Although some significant advances have been achieved in HCC treatments, poor prognoses and high recurrence risks have been a major challenge to researchers. Currently, surgical resection is the main treatment option for HCC patients; however, the complexities arising from surgery can reduce the therapeutic effect and the survival rate of patients $(4,5)$. Accordingly, it is urgent to find more effective and alternative therapeutic strategies which may benefit HCC patients.

Signal transducer and activator of transcription 3 (STAT3) is an important transcription factor that plays an essential role in relaying extracellular signals initiated by cytokines and growth factors from the cytoplasm to the nucleus (6-9). Following activation, phosphorylated STATs dimerize and translocate to the nucleus where they regulate the expression of numerous critical genes involved in cell cycle progression, proliferation and survival $(10,11)$. The constitutive activation of STAT3 is frequently detected in primary human cancer cells including HCC cells (12). These reports indicate that constitutive activation of STAT3 is one of the important pathways which contributes to the oncogenesis of $\mathrm{HCC}$ and can serve as an attractive therapeutic target for HCC.

Natural products have received recent interest as therapeutic agents for HCC due to their relatively few side effects and have long been used as alternative remedies for a variety of diseases including cancer $(13,14)$. Rubus aleaefolius Poir. is a major genus of the rose family, Rosaceae, generally used as a folk medicine to treat various types of hepatic disease including HCC. Our previous studies demonstrated that total alkaloids of Rubus aleaefolius Poir. (TARAP) inhibited HCC growth in vivo and in vitro via activation of mitochondrialdependent apoptosis (15). However, the precise mechanism of its anticancer activity remains largely unclear. To further 
elucidate its antitumor mechanism of action, in the present study we evaluated the efficacy of TARAP against tumor growth in vitro and in vivo and investigated the underlying molecular mechanisms.

\section{Materials and methods}

Materials and reagents. Dulbecco's modified Eagle's medium (DMEM), fetal bovine serum (FBS), penicillin-streptomycin, Trypsin-EDTA and TRIzol reagent were purchased from Invitrogen (Carlsbad, CA, USA). SuperScript II reverse transcriptase was obtained from Promega (Madison, WI, USA). Antibodies for PCNA, cyclin-dependent kinase (CDK) 2, cyclinE, CDK4, cyclinD1 and p21 were obtained from Santa Cruz Biotechnology, Inc. (Santa Cruz, CA, USA), and the cell cycle detection kit was obtained from Becton-Dickinson (San Jose, CA, USA). All other chemicals, unless otherwise stated, were obtained from Sigma (St. Louis, MO, USA). The roots of Rubus alceifolius Poir. were collected from Anxi of Fujian Province, identified and authenticated by experts in Fujian University of Tradional Chinese Medicine.

Preparation and content of TARAP. The preparation of TARAP was performed as previously described (15). The roots of Rubus alceifolius Poir. were collected from Anxi of Fujian Province, identified and authenticated by experts in our University, and the alkaloids were extracted.

Cell culture. Human HCC HepG2 cells were obtained from the American Type Culture Collection (ATCC; Manassas, VA, USA). The cells were grown in DMEM containing $10 \%(\mathrm{v} / \mathrm{v})$ FBS, and $100 \mathrm{U} / \mathrm{ml}$ penicillin and $100 \mu \mathrm{g} / \mathrm{ml}$ streptomycin in a $37^{\circ} \mathrm{C}$ humidified incubator with $5 \% \mathrm{CO}_{2}$. The cells were subcultured at $80-90 \%$ confluency.

Colony formation. HepG2 cells were seeded into 6-well plates at a density of $1 \times 10^{5}$ cells/well in $2 \mathrm{ml}$ medium. After treatment with various concentrations of TARAP for $24 \mathrm{~h}$, the cells were collected and then reseeded into 6-well plates at a density of $1 \times 10^{3}$ cells/well. Following incubation for 8 days in a $37^{\circ} \mathrm{C}$ humidified incubator with $5 \% \mathrm{CO}_{2}$, the formed colonies were fixed with $10 \%$ formaldehyde, stained with $0.01 \%$ crystal violet and counted. Cell survival was calculated by normalizing the survival of the control cells as $100 \%$.

Cell cycle analysis. The cell cycle analysis was carried out by flow cytometry using fluorescence activated cell sorting (FACSCalibur; Becton-Dickinson) and propidium iodide (PI) staining. Subsequent to treatment with various concentrations of TARAP for $24 \mathrm{~h}, \mathrm{HepG} 2$ cells were collected and adjusted to a concentration of $1 \times 10^{6}$ cells $/ \mathrm{ml}$, and fixed in $70 \%$ ethanol at $4^{\circ} \mathrm{C}$ overnight. The fixed cells were washed twice with cold PBS, and then incubated for $30 \mathrm{~min}$ with RNase $(8 \mu \mathrm{g} / \mathrm{ml})$ and PI $(10 \mu \mathrm{g} / \mathrm{ml})$. The fluorescent signal was detected through the FL2 channel, and the proportion of DNA in different phases was analyzed using ModfitLT v3.0 (Verity Software House, Topsham, MA, USA).

In vivo tumor xenograft study. HepG2 cells were grown in culture and then detached by trypsinization, washed and resus- pended in serum-free DMEM. Six-week-old athymic BALB/c $\mathrm{nu} / \mathrm{nu}$ male mice received an s.c. injection of $4 \times 10^{6} \mathrm{HepG} 2$ cells mixed with Matrigel (1:1) in the right flank to initiate tumor growth. After 7 days of xenograft implantation when the tumor size reached $3 \mathrm{~mm}$ in diameter, mice were randomly divided into two groups and gavaged with the following: i) control group $(\mathrm{n}=10)$, physiological saline (PS); and ii) TARAP group $(\mathrm{n}=10), 3 \mathrm{~g} / \mathrm{kg} /$ day dose of TARAP in PS. All treatments were administered 5 days weekly for 21 days. At the end of the experiment, tumors were excised, and part of the tumor was fixed in buffered formalin and the remaining was stored at $-80^{\circ} \mathrm{C}$ for molecular analyses.

Immunohistochemical analysis. Tumor samples were fixed with $10 \%$ formaldehyde for $12 \mathrm{~h}$ and subsequently processed conventionally for paraffin-embedded tumor slides. The slides were subjected to antigen retrieval and the endogenous peroxidase activity was blocked with $3 \%$ hydrogen peroxide for $10 \mathrm{~min}$. The sections were incubated with $1 \%$ bovine serum albumin in order to decrease non-specific staining and reduce endogenous peroxidase activity. For immunohistochemical staining, the sections were incubated with antibodies against phosphorylated STAT3 (pSTAT3), PCNA, CDK2, cyclinE, cyclinD1, CDK4 or p21 (all in 1:200 dilution; Santa Cruz Biotechnology, Inc.). After washing with PBS, slides were incubated with biotinylated secondary antibody followed by conjugated horseradish peroxidase (HRP)-labeled streptavidin (Dako) and then washed with PBS. The slides were then incubated with diaminobenzidine (DAB, Sigma) as the chromogen, followed by counterstaining with diluted Harris' hematoxylin (Sigma). After staining, five high-power fields (x400) were randomly selected in each slide, and the average proportion of positive cells in each field were counted using the true color multi-functional cell image analysis management system (Image-Pro Plus, Media Cybernetics, USA). To rule out any non-specific staining, PBS was used to replace the primary antibody as a negative control.

RNA extraction and RT-PCR analysis. The expression levels of CDK2, CDK4, cyclinD1, cyclinE and p21 genes were detected by RT-PCR. Total RNA was isolated with TRIzol reagent. Oligo(dT)-primed RNA $(1 \mu \mathrm{g})$ was reverse-transcribed with SuperScript II reverse transcriptase according to the manufacturer's instructions. The obtained cDNA was used to determine the mRNA amount of CDK2, CDK4, cyclinD1, cyclinE and p21 by PCR. GAPDH was used as an internal control.

Statistical analysis. All data are the means of three determinations, and data were analyzed using the SPSS Package for Windows (v11.5). Statistical analysis of the data was performed with the Student's t-test and ANOVA. Differences with $\mathrm{P}<0.05$ were considered to indicate a statistically significant result.

\section{Results}

TARAP inhibits the proliferation of HepG2 cells. A colony formation assay was used to assess the proliferation of HepG2 cells. As shown in Fig. 1A and B, TARAP treatment dose-dependently reduced the cell survival rate by $27-61 \%$ as compared to the untreated control cells $(\mathrm{P}<0.01)$. 


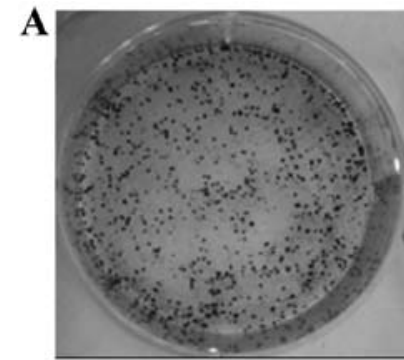

TARAP $0 \mathrm{mg} / \mathrm{ml}$

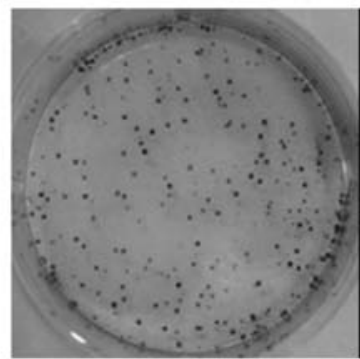

TARAP $0.75 \mathrm{mg} / \mathrm{ml}$

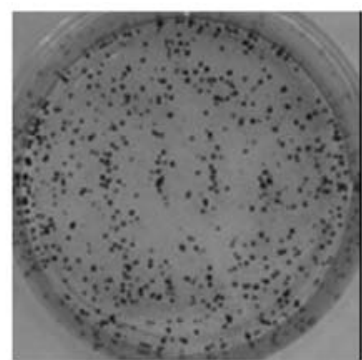

TARAP $0.25 \mathrm{mg} / \mathrm{ml}$

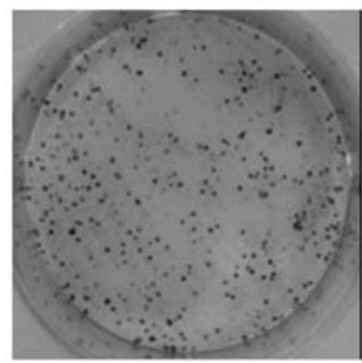

TARAP $1.0 \mathrm{mg} / \mathrm{ml}$

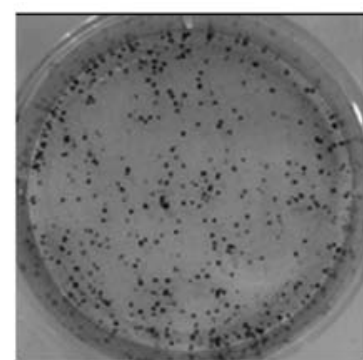

TARAP $0.50 \mathrm{mg} / \mathrm{ml}$

B

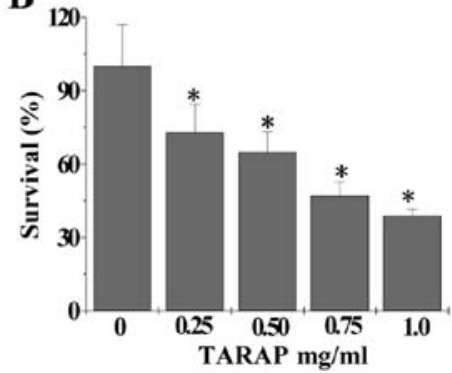

Figure 1. Effect of total alkaloids of Rubus aleaefolius Poir. (TARAP) on HepG2 cell survival. (A) Cells were treated with the indicated concentrations of TARAP for $24 \mathrm{~h}$. Cell survival was determined by colony formation analysis. Images are representative of three independent experiments. (B) Quantification of colony formation analysis. The data were normalized to the survival of the control cells and are shown as averages with SD (error bars) from at least three independent experiments. ${ }^{*} \mathrm{P}<0.05$ vs. control cells.

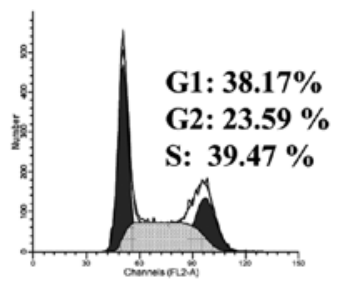

TARAP 0mg/ml

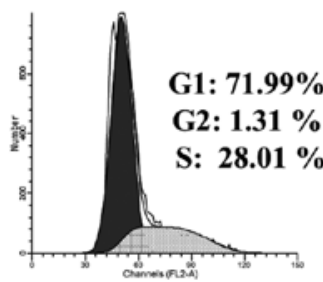

TARAP $0.75 \mathrm{mg} / \mathrm{ml}$

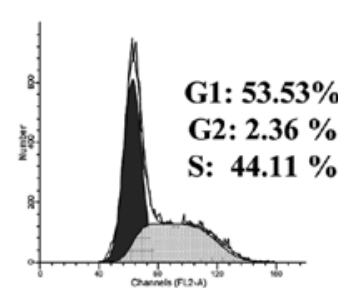

TARAP $0.25 \mathrm{mg} / \mathrm{ml}$

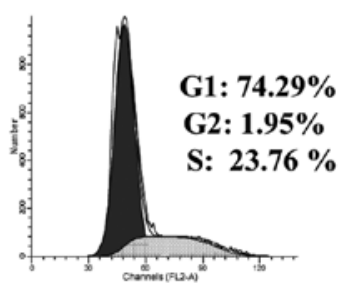

TARAP $1.0 \mathrm{mg} / \mathrm{ml}$

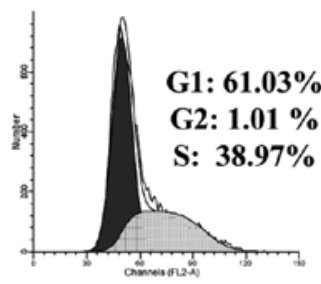

TARAP $0.50 \mathrm{mg} / \mathrm{ml}$

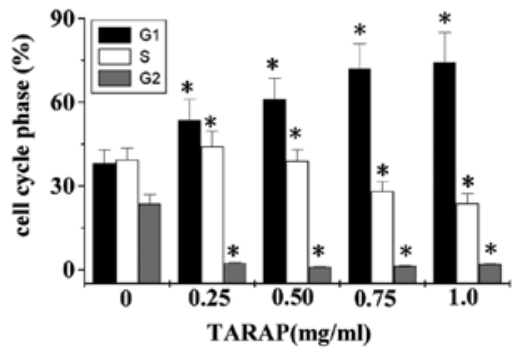

B

Figure 2. Effect of total alkaloids of Rubus aleaefolius Poir. (TARAP) on the cell cycle progression in HepG2 cells. (A) Cells were treated with the indicated concentrations of TARAP for $24 \mathrm{~h}$, stained with propidium iodide and analyzed by FACS. The proportion of DNA in the different phase was calculated using ModfitLT v3.0 software. (B) Data shown are averages with SD (error bars) from three independent experiments. "P $<0.05$ vs. control cells.

TARAP blocks the G1/S progression of HepG2 cells. The effect of TARAP on the G1 to S progression in HepG2 cells was examined via PI staining followed by FACS analysis. As shown in Fig. 2, the percentage of cells in the G1 phase following treatment with $0,0.25,0.5,0.75$ and $1.0 \mathrm{mg} / \mathrm{ml}$ of TARAP was $38.17 \pm 4.69,53.53 \pm 7.51,61.03 \pm 7.56,71.99 \pm 8.91$ and $74.29 \pm 10.57 \%$, respectively $(\mathrm{P}<0.01)$, indicating that TARAP inhibits HepG2 proliferation by arresting the cell cycle in the $\mathrm{G} 1$ phase.
TARAP suppresses STAT3 phosphorylation and cancer cell proliferatiom in HCC xenograft tumors in mice. STAT3 plays an important role in cell survival and proliferation. pSTAT3 leads to promotion of cell proliferation. We therefore examined the effect of TARAP on STAT3 phosphorylation in tumor tissues using IHC assay. As shown in Fig. 3, the percentage of pSTAT3-positive cells in the control and TARAP-treated xenograft tumors was $45.17 \pm 7.72$ and $21.67 \pm 3.01 \%$, respectively $(\mathrm{P}<0.01)$, suggesting that TARAP treatment significantly 
$\mathbf{A}$
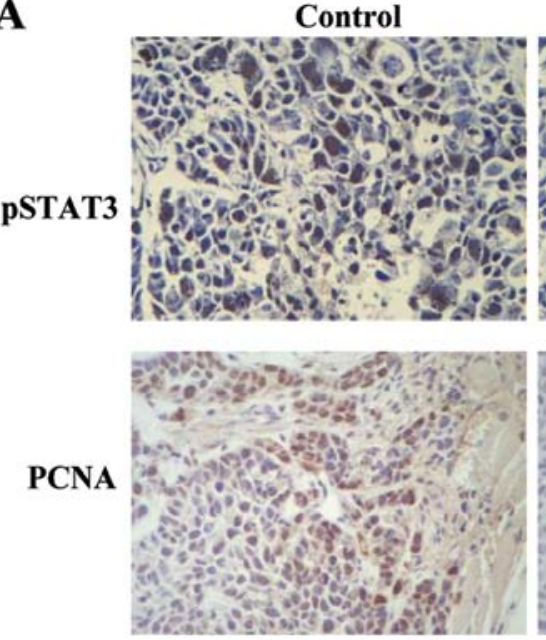
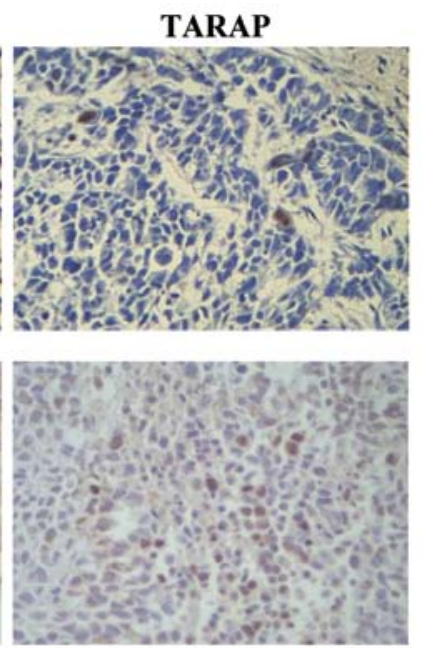

B
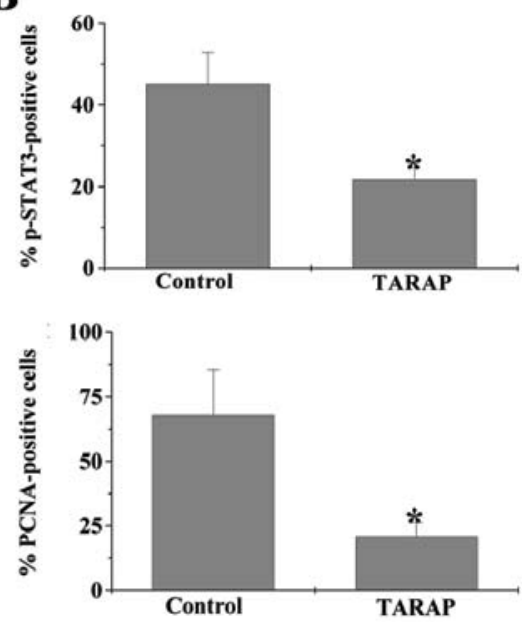

Figure 3. Effect of total alkaloids of Rubus aleaefolius Poir. (TARAP) on phosphorylation of STAT3 (pSTAT3) in hepatocellular carcinoma (HCC) xenograft tumors in mice and cell proliferation. (A) At the end of the experiment, tumor tissues from control and TARAP-treated group were processed for immunohistochemical (IHC) staining for pSTAT3 or PCNA. Representative images were captured at a magnification x400. (B) Quantification of IHC assay is presented as the percentage of positively stained cells. Data shown are averages with $\mathrm{SD}$ (error bars) from 10 mice in each group. ${ }^{*} \mathrm{P}<0.01$ vs. controls.

suppresses the activation of STAT3 in HCC mice. To determine whether the inhibitory effect of TARAP on cancer growth is due to cell proliferation, we examined the expression of PCNA. As shown in Fig. 3, the percentage of PCNA-positive cells in control or TARAP-treated mice was $67.83 \pm 17.61$ and $20.83 \pm 5.42 \%$, respectively. Taken together, these data suggest that TARAP inhibits the proliferation of HCC cells via suppression of pSTAT3.

TARAP regulates the expression of $C D K 2, C D K 4$, cyclinD1, cyclinE, p21 in HCC xenograft tumors in mice. To explore the mechanism of the antiproliferative activity of TARAP, we performed RT-PCR and IHC assay to respectively examine the mRNA and protein expression of CDK2, CDK4, cyclinD1, cyclinE and p21 in HCC tumors in mice. Results of the RT-PCR showed that TARAP treatment reduced the mRNA expression of CDK2, CDK4, cyclinD1, cyclinE, in tumors, whereas p21 was increased (Fig. 4A). Data from IHC assay indicated that the protein expression patterns of CDK2, CDK4, cyclinD1, cyclinE and p21 were similar to their respective mRNA levels. The percentage of CDK2-, CDK4-, cyclinD1-, cyclinEand p21-positive cells in the control group was $28.67 \pm 4.88$, $58.33 \pm 10.03,37.67 \pm 5.39,46.17 \pm 6.56$ or $32.67 \pm 4.81 \%$, whereas that in TARAP-treated mice was $17.67 \pm 2.53,24.33 \pm 3.48$, $18.67 \pm 3.23,25.33 \pm 3.59$ and $89.5 \pm 12.44 \%$ (Fig. 4B).

\section{Discussion}

Although curative therapies such as surgical resection, liver transplantation and ablative therapies have led to improvement in the survival of patients with HCC $(2,3)$, unfortunately, most patients are still diagnosed at advanced stages and receive only palliative treatments $(16,17)$. In addition, many currently used anticancer agents possessing intrinsic cytotoxicity to normal cells limit the effectiveness of current cancer therapies. Natural products have relatively fewer side effects and have been used clinically for thousands of years to treat various types of diseases, including cancer $(13,14)$. As a natural product, Rubus aleaefolius Poir. has exhibited strong activity against liver disease including liver cancer. However, the precise mechanism of its anticancer activity remains largely unclear.

Cancer cells are characterized by uncontrolled proliferation (18). Therefore, inhibiting excessive proliferation of tumor cells is one of the key approaches for the development of anticancer drugs. Here, using colony formation assay, we demonstrated that TARAP inhibited the proliferation of human HCC HepG2 cells in a dose-dependent manner. The transcription factor STAT3 is essential for cell survival and proliferation. Constitutive activation of STAT3 is one of the important pathways which contributes to the oncogenesis in HCC (12). Our data showed that TARAP suppressed the activation of STAT3. Eukaryotic cell proliferation is primarily regulated by the cell cycle. Cell cycle progression is tightly regulated by cyclins, $\mathrm{CDKs}$, $\mathrm{CDK}$ inhibitors (CKIs) and many other factors. Cyclins associated with CDKs are the primary regulators of CDK activity. The activation of CDK4 plays an important role in the passage through the G1 restriction point when the cell becomes committed to proceed through the cell cycle, while CDK2 activation plays an essential role in the transition into S-phase and DNA synthesis. CyclinD1 expression, which is induced during G1 phase in response to mitogens, complexes with and activates CDK4. CDK2 is regulated primarily by cyclinE during G1/S transition and $S$ phase, respectively $(19,20)$. The KIP protein p21 is generally believed to act as a negative regulator of cell cycle progression. As a proliferation inhibitor, p21 protein plays an important role in $\mathrm{G} 1$ arrest by binding to and inhibiting the activity of cyclin-CDK complexes; in contrast, when bound to PCNA, p21 is degraded more slowly compared with p21 binding to cyclin/CDK, which increases the rate of p21 degradation (21). Using a HCC mouse xenograft model, in the present study we found that TARAP decreased the phosphorylation activation of STAT3, Consequently, the inhibitory effect of TARAP on STAT3 activation resulted in the suppression of cell proliferation and cell cycle arrest. Moreover, TARAP treatment profoundly reduced the expression of PCNA, cyclinE, CDK2, 
$\mathbf{A}$

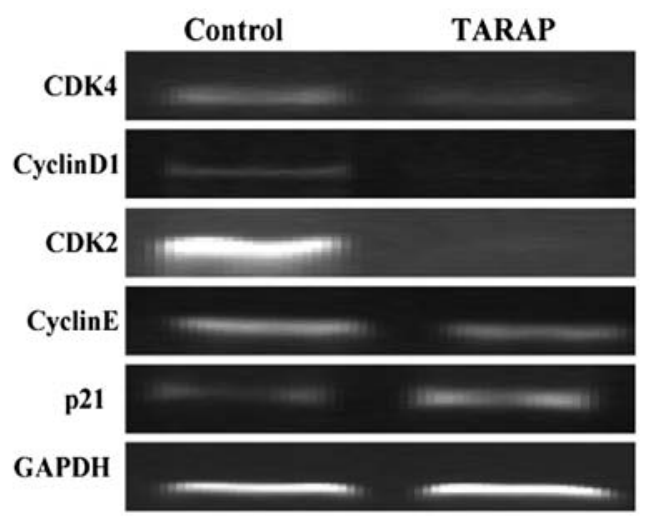

B

Control

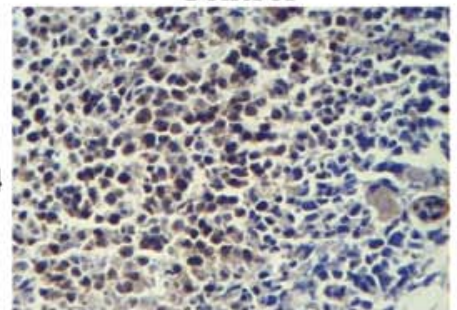

CDK4

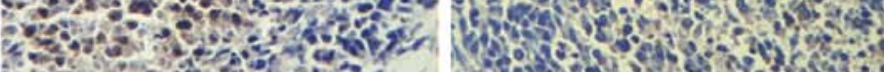
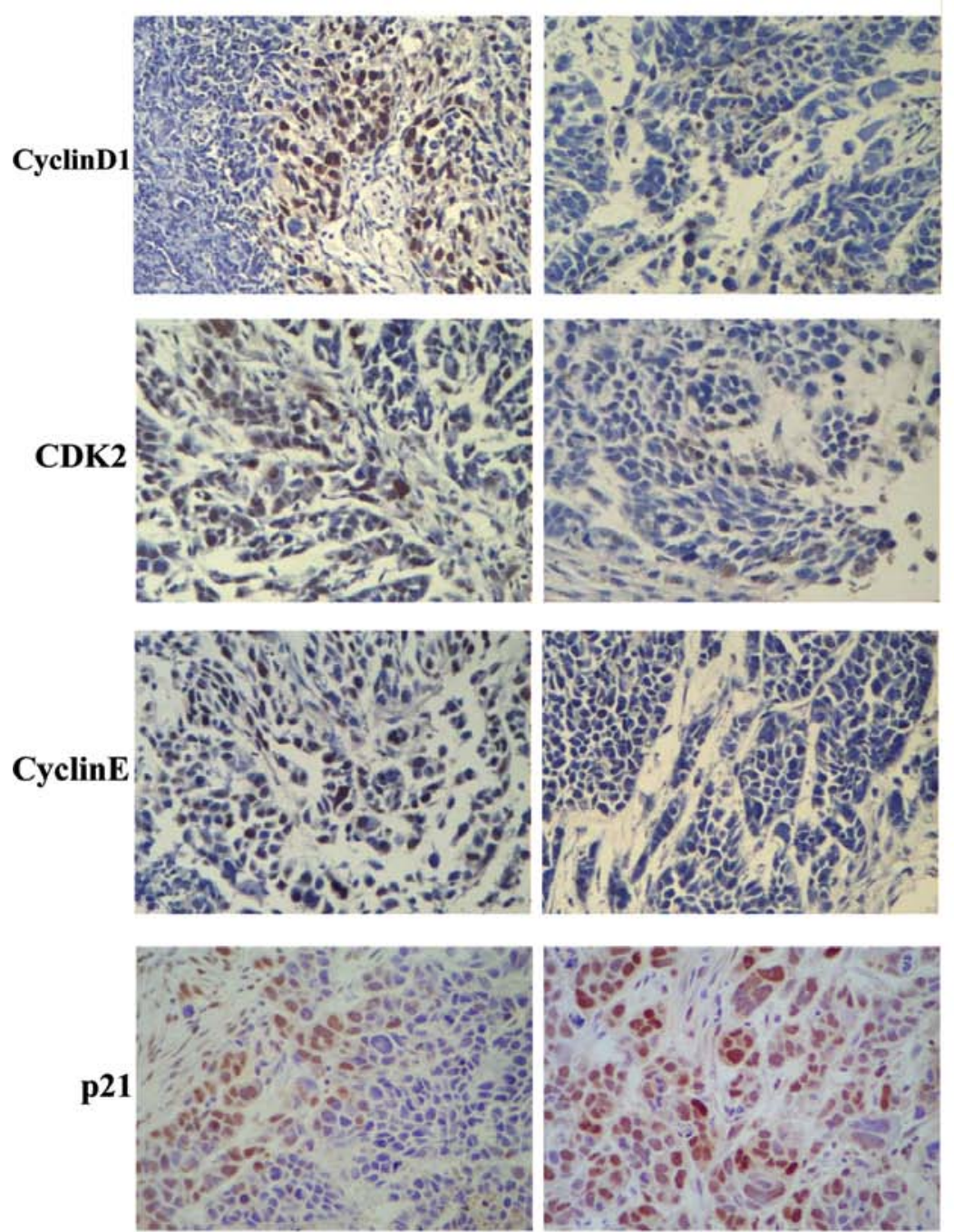

TARAP
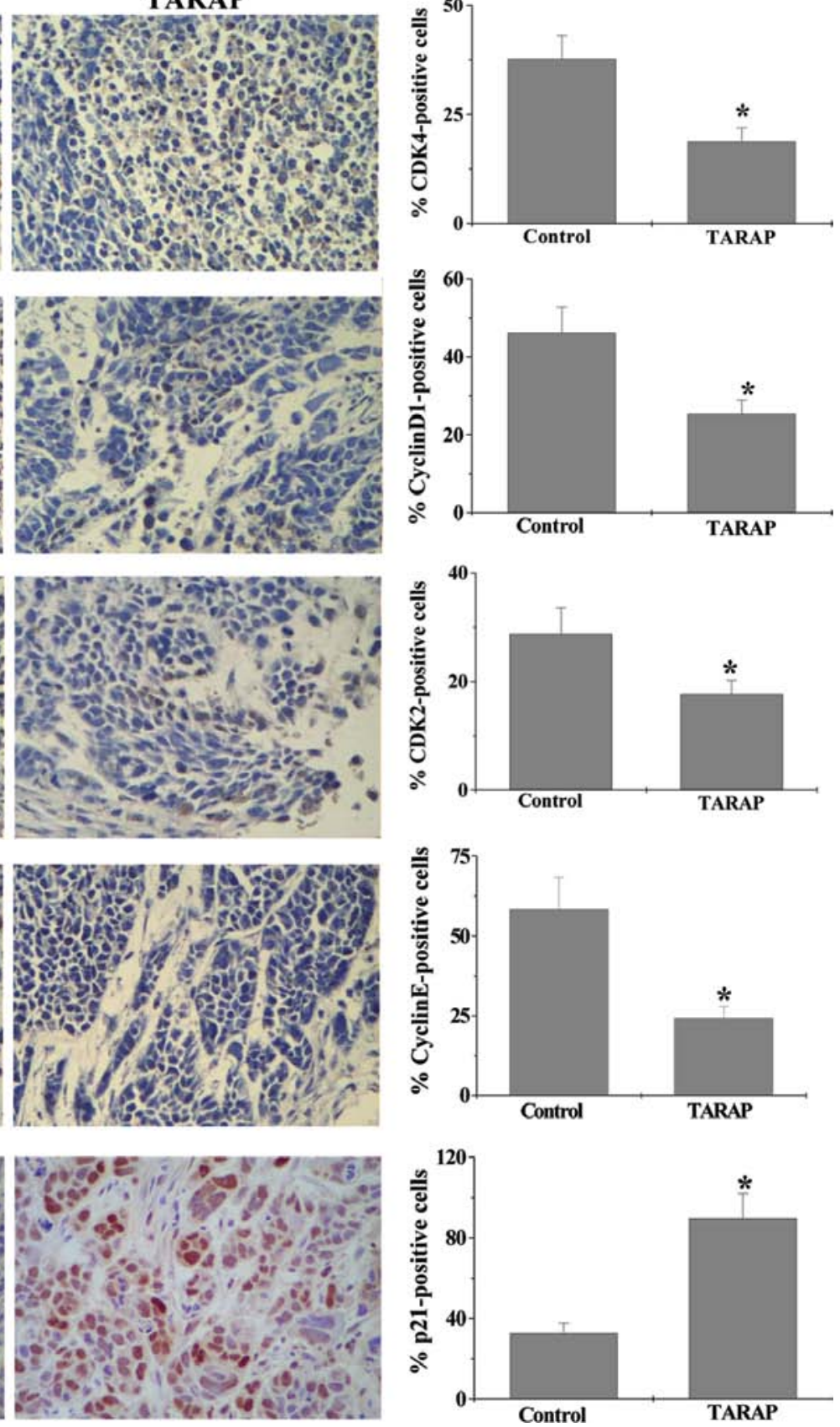

Figure 4. Effect of total alkaloids of Rubus aleaefolius Poir. (TARAP) on the expression of cyclin-dependent kinase (CDK) 4, cyclinD1, CDK2, cyclinE and p21 in HCC xenograft tumors in mice. (A) The mRNA expression of CDK4, cyclinD1, CDK2, cyclinE and p21 in tumor tissues from the control and TARAPtreated groups was determined by RT-PCR. GAPDH was used as an internal control. (B) The protein expression was analyzed via immunohistochemical (IHC) assay. Representative images were captured at a magnification of x400. Quantification of IHC assay is presented as the percentage of positively stained cells. Data shown are averages with SD (error bars) from 10 mice in each group. ${ }^{*} \mathrm{P}<0.01$ vs. controls. 
cyclinD1 and CDK4, as well as increased expression of antiproliferative $\mathrm{p} 21$.

In conclusion, for the first time we demonstrated that TARAP inhibits growth in vivo and in vitro via inhibition of proliferation and cell cycle arrest, which is mediated by the suppression of the STAT3 pathway. Our findings suggest that TARAP may be a potential novel therapeutic agent for the treatment of cancers with constitutive activation of STAT3.

\section{Acknowledgements}

The present study was supported by the Nature Science Foundation of Fujian Province of China (no. 2010J01191 and 2010J01194); and the project was sponsored by Medical Originality Foundation of Fujian Province of China (no. 2009-CX-18).

\section{References}

1. El-Serag HB: Hepatocellular carcinoma. N Engl J Med 365: 1118-1127, 2011

2. Jemal A, Ward E, Hao Y and Thun M: Trends in the leading causes of death in the United States, 1970-2002. JAMA 294 1255-1259, 2005.

3. Bosch FX, Ribes J, Díaz M and Cléries R: Primary liver cancer: worldwide incidence and trends. Gastroenterology 127: S5-S16, 2004.

4. Patel M, Shariff MI, Ladep NG, et al: Hepatocellular carcinoma: diagnostics and screening. J Eval Clin Pract 18: 335-342, 2012.

5. Shariff MI, Cox IJ, Gomaa AI, et al: Hepatocellular carcinoma: current trends in worldwide epidemiology, risk factors, diagnosis and therapeutics. Expert Rev Gastroenterol Hepatol 3: 353-367, 2009.

6. Frank DA: STAT3 as a central mediator of neoplastic cellular transformation. Cancer Lett 251: 199-210, 2007.

7. Germain D and Frank DA: Targeting the cytoplasmic and nuclear functions of signal transducers and activators of transcription 3 for cancer therapy. Clin Cancer Res 13: 5665-5669, 2007.
8. Turkson J and Jove R: STAT proteins: novel molecular targets for cancer drug discovery. Oncogene 19: 6613-6626, 2000.

9. Calò VV, Migliavacca M, Bazan V, et al: STAT proteins: from normal control of cellular events to tumorigenesis. J Cell Physiol 197: 157-168, 2003.

10. Bromberg J and Darnell JE Jr: The role of STATs in transcriptional control and their impact on cellular function. Oncogene 19: 2468-2473, 2000.

11. Aggarwal BB, Kunnumakkara AB, Harikumar KB, et al: Signal transducer and activator of transcription-3, inflammation, and cancer: how intimate is the relationship? Ann NY Acad Sci 1171: 59-76, 2009.

12. Moran DM, Mattocks MA, Cahill PA, et al: Interleukin-6 mediates $\mathrm{G}(0) / \mathrm{G}(1)$ growth arrest in hepatocellular carcinoma through a STAT3-dependent pathway. J Surg Res 147: 23-33, 2008.

13. Gordaliza M: Natural products as leads to anticancer drugs. Clin Transl Oncol 9: 767-776, 2007.

14. Ji HF, Li XJ and Zhang HY: Natural products and drug discovery. Can thousands of years of ancient medical knowledge lead us to new and powerful drug combinations in the fight against cancer and dementia? EMBO Rep 10: 194-200, 2009.

15. Zhao JY, Chen XZ, Lin W, et al: Total alkaloids of Rubus aleaefolius Poir. inhibit hepatocellular carcinoma growth in vivo and in vitro via activation of mitochondrial-dependent apoptosis. Int J Oncol 42: 971-978, 2013.

16. Bruix J and Sherman M: Management of hepatocellular carcinoma. Hepatology 42: 1208-1236, 2005.

17. Llovet JM, Burroughs A and Bruix J: Hepatocellular carcinoma. Lancet 362: 1907-1917, 2003.

18. Evan GI and Vousden KH: Proliferation, cell cycle and apoptosis in cancer. Nature 411: 342-348, 2001.

19. Morgan DO: Principles of CDK regulation. Nature 374: 131-134, 1995.

20. Sherr CJ and Roberts JM: CDK inhibitors: positive and negative regulators of G1-phase progression. Genes Dev 13: 1501-1512, 1999.

21. Cayrol C and Ducommun B: Interaction with cyclin-dependent kinases and PCNA modulates proteasome-dependent degradation of p21. Oncogene 17: 2437-2444, 1998. 